\title{
Should the CAG advocate for resources with government and governmental agencies?
}

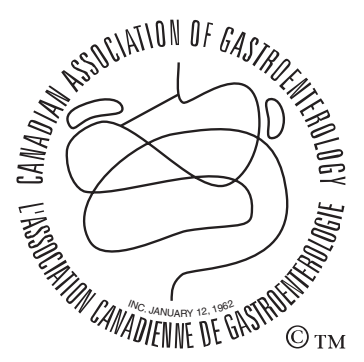

En français voir page 16

\author{
Philip M Sherman MD FRCPC \\ President, CAG
}

John L Wallace PhD

Past President, CAG

Cor many years, the Canadian Association of

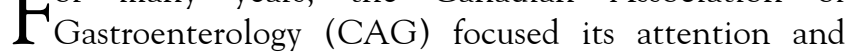
resources on advancing postgraduate medical education in the subspecialty. This focus culminated in the development of a highly successful annual Canadian Digestive Disease Week. More recently, the CAG also became engaged in supporting research opportunities for trainees and for research activities of the membership. The CAG now supports $\$ 1.5$ million annually of Canadian gastroenterology research. This has clear benefits toward the advancement of gastroenterology as a whole and the training of the next generation of investigators in the discipline.

The Canadian Digestive Health Foundation has been formed to concentrate on the patient and public sectors; for example, to disseminate patient educational materials and to emphasize the burden of illnesses affecting the gastrointestinal tract on Canadians and the Canadian health care system. Over the past 10 years, these initiatives were undertaken following a roadmap provided by a strategic planning survey that was completed by leadership of the CAG of the time.

Although we have been highly successful in the achievements noted above, our membership is expecting, and deserves, even more. Planning for the future requires a clear set of goals and objectives with resources put in place to make plans become a reality. During this year, we have taken on the challenge of developing and circulating a new strategic survey for the CAG based on the needs and visions for the future of the CAG membership-at-large. To date, more than 200 surveys have been returned, and we plan to have presented a summary of the results at the Annual General Meeting at CDDW-2003 in Banff, Alberta.

In addition, the CAG is increasingly interacting with federal and provincial governmental agencies, to lobby for the resources that are required for patients under our subspecialty care to receive new indications for endoscopic evaluations (for example, colon cancer screening initiatives). Moreover, new therapeutic advances are often costly to an already stretched-to-the-limit health care system (eg, infliximab infusions used to induce remissions in intractable chronic inflammatory bowel diseases). Nevertheless, it is important that our clinician members and their patients have appropriate access to these new advances in the subspecialty. The CAG will continue to interact with government and payers to advocate appropriate access and sufficient resources.

In the past year, the CAG has been involved in a number of letter-writing campaigns to enhance support for issues pertaining to gastrointestinal health and disease. On our behalf, the CAG National Executive Director attended the

The CAG is proud to acknowledge its Benefactor Corporate Sponsors:
Abbott Laboratories Ltd.
AstraZeneca Canada Inc.
Axcan Pharma Inc.
Janssen-Ortho Inc. 
second annual "Health Research Day On The Hill" in Ottawa in October, 2002 - an advocacy day supported by the Canadian Health Research Council. A number of societies, charitable foundations, and researchers met with over 150 Members of Parliament to deliver the message of the need for increased research and development funding, through the Canadian Institutes of Health Research, in Canada. The goal of this investment is to secure the necessary research base investment that will support the future of the Canadian health care system.

Considering the future: we must do more! The Past Presidents of our organization, through the Council of the
Past Presidents, have been charged with developing for the CAG a range of options available for presenting the issues that affect us, and our patients, to provincial and federal sources of funding in the most effective, forceful and cogent manner. The merits of hiring a lobbyist and supporting members-at-large to travel to Parliament Hill and to the headquarters of the Canadian Institutes of Health Research are examples of initiatives that we may consider. In this regard, the American Gastroenterological Association already has seen the merits of taking such an approach in the United States of America (AGA News, November, 2002). 


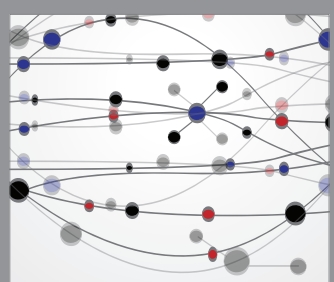

The Scientific World Journal
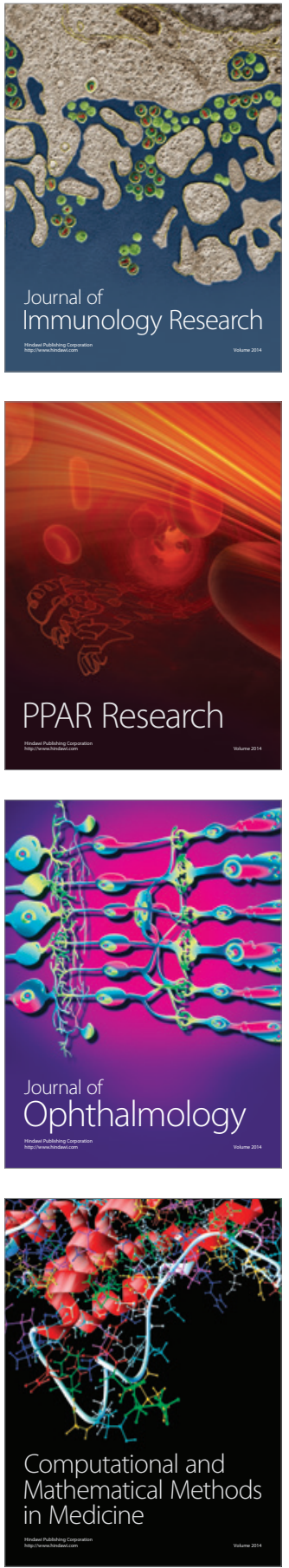

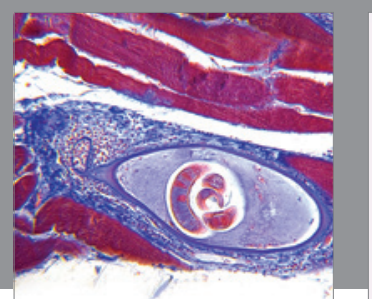

Gastroenterology Research and Practice

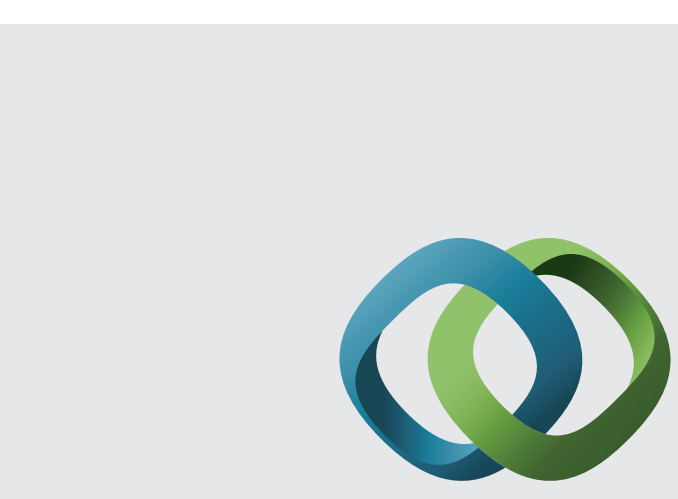

\section{Hindawi}

Submit your manuscripts at

http://www.hindawi.com
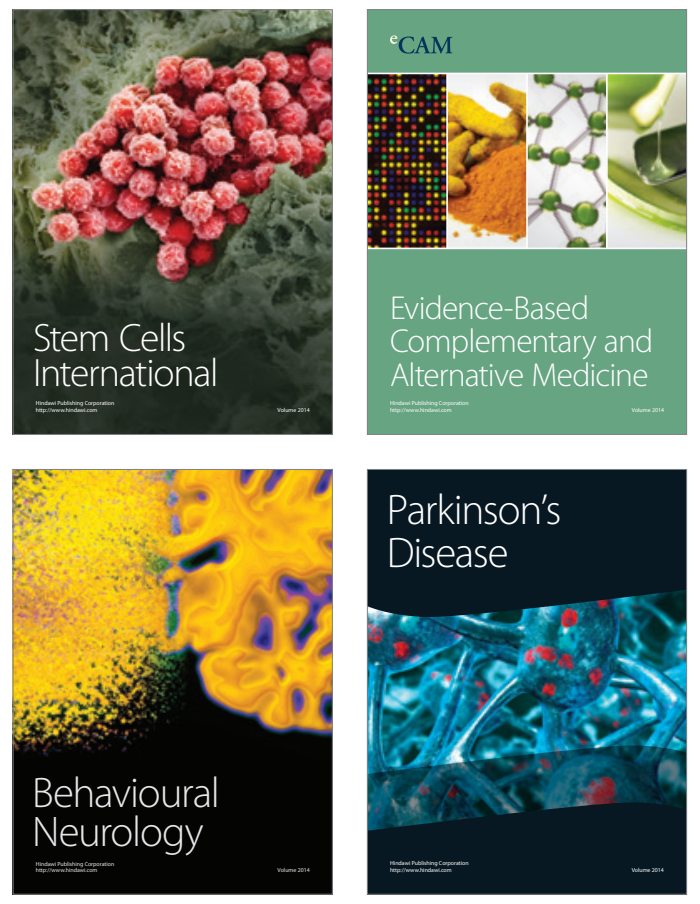
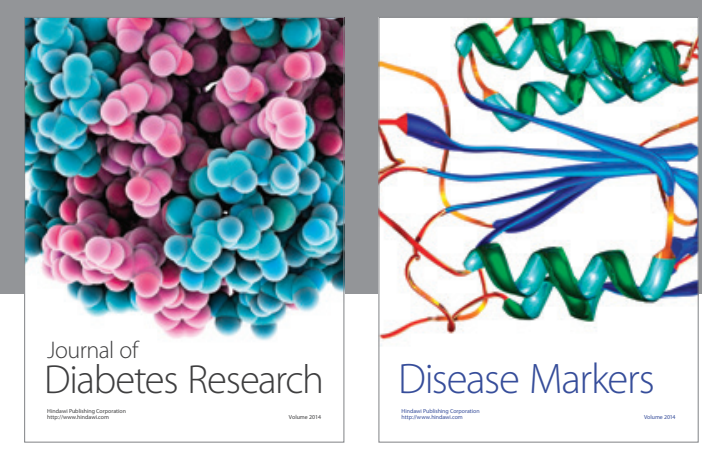

Disease Markers
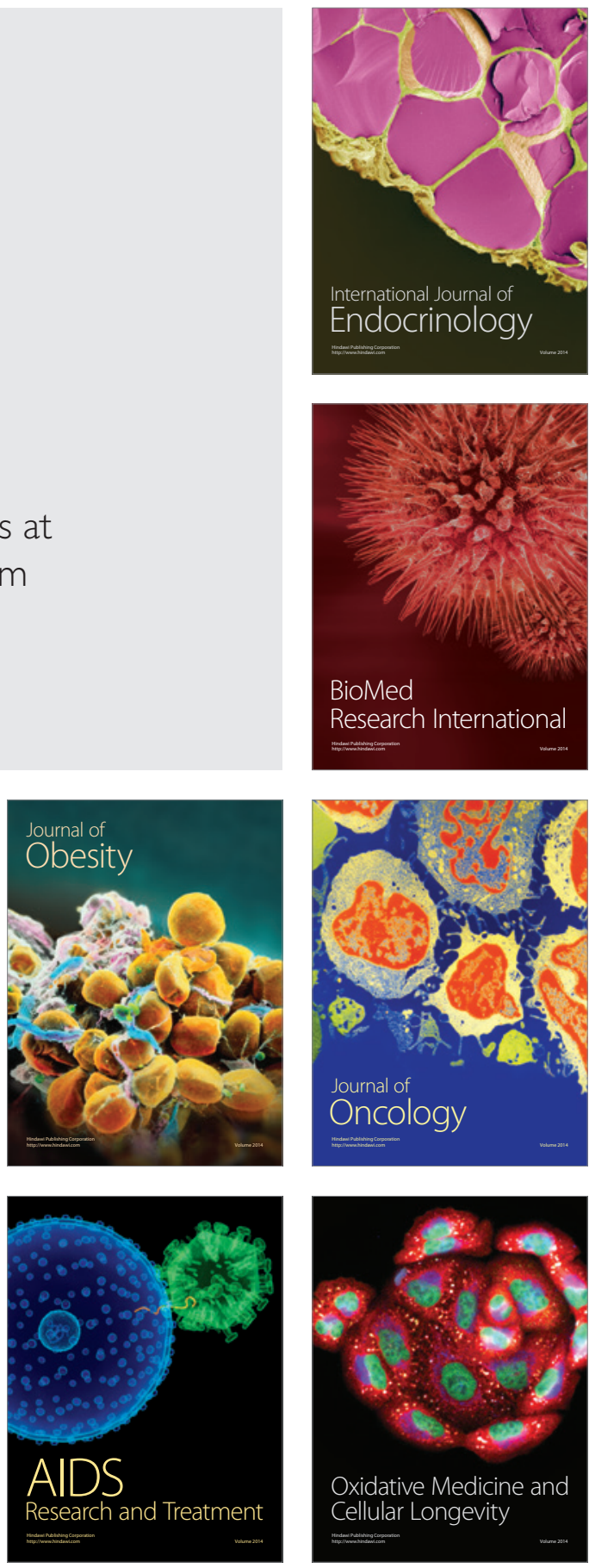